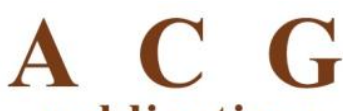

publications

Rec. Nat. Prod. 11:6 (2017) 552-557

records of natural

products

\title{
Chemical and Biological Investigation of Ochrosia elliptica Labill. Cultivated in Egypt
}

\author{
Riham A. El-shiekh ${ }^{1}$, Dalia A. Al-Mahdy ${ }^{1}$, Mohamed S. Hifnawy, \\ Tzvetomira Tzanova ${ }^{2}$, Emilie Evain-Bana ${ }^{2}$, Stéphanie Philippot ${ }^{2}$, \\ Denyse Bagrel $^{2}$ and Essam A. Abdelsattar ${ }^{1, *}$ \\ ${ }^{1}$ Department of Pharmacognosy, Faculty of Pharmacy, Cairo University, Kasr El Aini st., \\ P.B. 11562, Egypt \\ ${ }^{2}$ Molecular Engineering Laboratory and Pharmacological Biochemistry (LIMBP), Jean Barriol \\ Institute, University of Lorraine, Metz, France
}

(Received March 03, 2017; Revised May 16,2017; Accepted May 24, 2017)

\begin{abstract}
The phytochemical investigation of Ochrosia eliptica leaves resulted in isolation and identification of eight compounds; lupeol, lupeol acetate, uvaol, ursolic acid, $\beta$-sitosterol glucoside, rutin, 8-methoxy and 9methoxy ellipticine. The ethanolic extract and fractions were studied for their cytotoxic, antioxidant and antiinflammatory activities. The cytotoxic activity was performed on human mammary adenocarcinoma (MCF7), its multidrug-resistant counterpart (VCREMS), estrogen receptor negative human metastatic breast adenocarcinoma cells (MDA-MB-231) and the non-cancerous, immortalized by telomerase, human breast epithelial cell line (hTERT-HME1). Additionally, the inhibitory potential on Cdc25s proteins was determined. The results showed that the dichloromethane (DCM) fraction and the major alkaloid; 9-methoxyellipticine exhibited high inhibitory activity against all tested cell lines particularly MCF7 and VCREMS cell lines, whereas the DCM fraction showed a significant inhibitory action on Cdc25 A isoform. In contrast, the $n$-butanol fraction and 9-methoxyellipticine displayed the highest antioxidant potential. The DCM fraction showed significant anti-inflammatory activity compared to indomethacin. This work comprises the first comprehensive work to be conducted on O. elliptica leaves showing its potential in multiple biological activities.
\end{abstract}

Keywords: Ochrosia elliptica; 9-methoxyellipticine; cytotoxicity; Cdc25s; anti-inflammatory. (C) 2017 ACG Publications. All rights reserved.

\section{Plant Source}

Ochrosia elliptica Labill. is a small tropical evergreen tree native to Oceania [1] and cultivated in Egypt for ornamental purposes. The leaves were collected from El-Orman Botanical Garden, Giza, Egypt. The plant was authenticated by Dr. Reem Samir Hamdy, Associate Professor of Taxonomy and Flora, Department of Botany, Faculty of Science, Cairo University and a voucher specimen (no. 28.12.2012) was deposited at the herbarium of the department of Pharmacognosy, Faculty of Pharmacy, Cairo University.

\footnotetext{
* Corresponding author: E- Mail: essam.abdelsattar@pharma.cu.edu.eg
} 


\section{Previous Studies}

O. elliptica is well known for ellipticine series of indole alkaloids isolated from the leaves and bark [1, 2], in addition to lignans, coumarins and phenolic acids [3]. Previous biological activities were concerned mainly with the cytotoxic activities of ellipticine [4]. Ellipticine and its derivatives primarily act via combined mechanisms of cell cycle arrest and induction of apoptotic pathways [5] against several cancer cell lines [6-9]. Herein, we thus report the cytotoxic activity of the ethanolic extract, as well as, the dichloromethane, $n$-butanol and alkaloidal fractions of $O$. elliptica leaves and the major isolated alkaloid against MCF-7, MDA-MB-231, VCREMS, hTERT-HME1 cell lines focusing on their cdc25s phosphatase inhibitory activity, along with determination of their antioxidant and in-vivo antiinflammatory activities; in an effort to provide further insight into this plant's profile.

\section{Present Study}

The ethanolic (95\%) extract of the leaves was fractionated into petroleum ether, dichloromethane (DCM) and $n$-butanol $(n$-BuOH). Based on a preliminary cytotoxic and antioxidant activity testing, the most active DCM and $n$-BuOH fractions were selected for further isolation procedures. The DCM fraction afforded compounds $\mathbf{1}$ - 5. Compounds $\mathbf{6}$ and $\mathbf{7}$ were isolated from the $n$-BuOH fraction. Compounds 8 and further amounts of compound $\mathbf{7}$ were isolated from the crude alkaloidal fraction.

Identification of the isolated compounds: The structures of compounds (1-8) were determined via MS, ${ }^{1} \mathrm{H}$ and ${ }^{13} \mathrm{C}$ NMR spectral analysis and identified as lupeol acetate (1), lupeol (2), uvaol (urs-12-ene-3, 28-diol) (3), ursolic acid (4), $\beta$-sitosterol glucoside (5), rutin (6), 8-methoxyellipticine (7) and 9methoxyellipticine (8) ( See supporting information). Interestingly, compounds 1-3, 5-6 were previously reported in different plants belonging to family Apocynaceae [10-12], nevertheless this is the first report for their isolation from O. elliptica. 8-Methoxyellipticine (7) was previously obtained through microbial transformation [13] and chemical synthesis from ellipticine [14], as well as, suggested to be isolated from $O$. sandwicensis [15]. Herein, we report the full assignement of 8-methoxyellipticine for the first time. 9-Methoxyellipticine was previously isolated from the barks of O. elliptica [2]. Structures of isolated compounds are depicted in Figure 1.

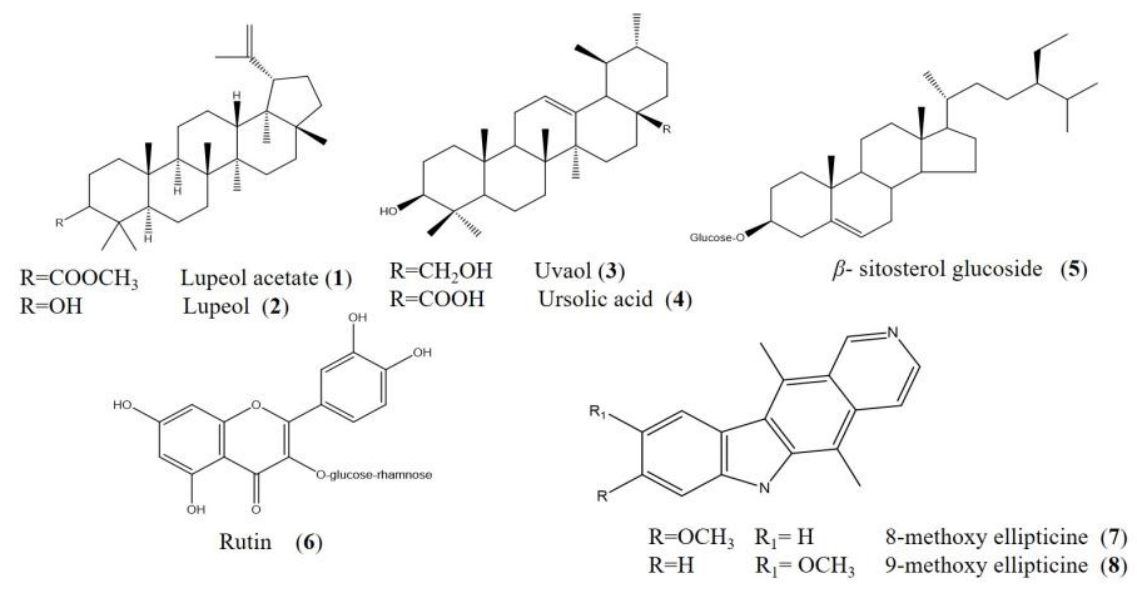

Figure 1. Structures of the isolated compounds from $O$. elliptica leaves

Cytotoxicity effects on cells: The results of the cytotoxic activity of the ethanolic, DCM, $n$-BuOH and the alkaloidal fractions, as well as, 9-methoxy ellipticine are summarized in Table 1 . The tested samples showed a dose-dependent cytotoxic activity. The DCM fraction displayed the highest cytotoxic activity against all tested cell lines at a dose of $200 \mu \mathrm{g} / \mathrm{mL}$ with $\mathrm{IC}_{50}$ values of $0.31 \pm 0.11,25.95 \pm 2.11$ and $48.85 \pm 5.49 \mu \mathrm{g} / \mathrm{mL}$ for MCF7, VCREMS and MDA-MB-231 cell lines, respectively followed by the alkaloidal and $n$-BuOH fractions exhibiting moderate to weak activity. Whereas, the major isolated alkaloid; 9-methoxyellipticine showed outstanding cytotoxic activity against all tested tumour cell lines 
with $\mathrm{IC}_{50}$ values of $0.39,1.9$ and $0.39 \mu \mathrm{mol}$ for MCF7, VCREMS and MDA-MB-231, respectively. The non-cancerous cell line hTERT-HME1 was very sensitive to all the tested samples with 76.7 to 95\% loss of cell viability. The results obtained for the DCM fraction are in agreement with the previous reports for the capability of pentacyclic triterpenes of the lupane and ursane types to act as multitarget agents that can assist in cancer treatment from different approaches [16-17], in addition, ellipticine was reported to inhibit the growth of MCF7 and MDA-MB-231 cell lines [7, 18]. It is interesting to note that, although 9-methoxyellipticine was the major compound in the alkaloidal fraction, nevertheless, it showed potent cytotoxic activity in contrast to the moderate activity observed for its parent fraction.

Table 1. In-vitro cytotoxic activity $\left(\mathrm{IC}_{50}\right)$ of the extracts and alkaloidal fractions of $O$. elliptica

\begin{tabular}{lllll}
\hline \multicolumn{1}{c}{ Test sample } & \multicolumn{2}{c}{ IC $_{\mathbf{5 0}}$ (Mean \pm S.D.) Cell lines } & \\
& MCF7 & VCREMS & MDA-MB-231 & hTERT-HME1 \\
\hline Ethanol extract & ND & ND & ND & ND \\
DCM fraction & $\mathbf{0 . 3 1} \pm \mathbf{0 . 1 1}$ & $25.95 \pm 2.11$ & $48.85 \pm 5.49$ & $48.38 \pm 1.7$ \\
$n$-BuOH fraction & ND & ND & ND & ND \\
Alkaloidal fraction & $31.16 \pm 12.8$ & $63.34 \pm 5.68$ & $40.22 \pm 8.35$ & $53.45 \pm 27.9$ \\
9-methoxyellipticine $(\mathbf{8})$ & $0.11 \pm 0.02(0.3985)$ & $0.34 \pm 0.01(1.90)$ & $0.11 \pm 0.01(0.3985)$ & $0.11 \pm 0.03(0.3985)$ \\
SV37 & $29.63 \pm 0.7(11.2)$ & ND & $25.132 \pm 1.0(9.5)$ & $47.883 \pm 1.3(18.1)$ \\
\hline
\end{tabular}

ND: not determined; $\mathrm{IC}_{50}: \mu \mathrm{g} / \mathrm{mL}(\mu \mathrm{M})$.

SV37: $2\{(7-M e t h o x y-2-o x o-2 H-C h r o m e n-y l)$ Methyl sulfanyl $\}$ Naphtoquinone

In vitro inhibition of phosphatase assay: The ethanolic, DCM and $n-\mathrm{BuOH}$ fractions of $O$. elliptica were evaluated for their ability to inhibit the activities of human Cdc25 A, B and C isoforms. The samples were tested at a dose of $4 \mathrm{mg} / \mathrm{mL}$ and the results are expressed as percentage of residual activity of Cdc25 phosphatases (Table 2). The obtained results indicated that the highest inhibitory activity was established for the DCM fraction followed by the ethanolic extract and finally the $n$-BuOH fraction compared to naphthoquinone as standard drug. The most potent inhibitory effect was observed against Cdc25A isoform, whereas Cdc25B was the least sensitive protein. Cdc25 phosphatases are considered interesting candidates within the context of research for new cancer therapy targets. Their inhibition allows slowing down of tumour growth and eventually improving cancer treatments. Numerous studies have associated cancer with over-expression of $\mathrm{Cdc} 25$ isoforms with this over-expression often being related to unfavourable prognosis [19]. Cdc25A and B have been described as oncogenes; since these proteins were upregulated in numerous tumours, including breast [20], hepatocellular [21] and other tumours. Considering the results described herein, the DCM fraction and its isolated compounds could be regarded as potential Cdc25 phosphatase inhibitors, in particular for Cdc25 A, which is in agreement with previous reports for lupeol [22], as well as ellipticine, which showed the ability to arrest MDAMB-231 cells with concomitant reduction in the expression of cyclin B, Cdc25 and Cdc2 levels [7].

Table 2. Inhibitory activity of the extracts of $O$. elliptica leaves against Cdc25s phosphatases

\begin{tabular}{llcl}
\hline \multirow{2}{*}{ Sample $(4 \mathrm{mg} / \mathrm{mL})$} & \multicolumn{3}{c}{ \% Residual activity (Mean \pm S.D.) } \\
\cline { 2 - 4 } & $\mathbf{C d c 2 5 ~ \mathbf { ~ }}$ & $\mathbf{C d c 2 5} \mathbf{~ B}$ & $\mathbf{C d c 2 5} \mathbf{C}$ \\
\hline Ethanol extract & $5.23 \pm 0.74$ & $41.78 \pm 4.69$ & $23.59 \pm 5.05$ \\
DCM fraction & $\mathbf{4 . 8 0} \pm \mathbf{0 . 9 4}$ & $32.37 \pm 7.17$ & $17.17 \pm 7.25$ \\
$n$-BuOH fraction & $11.54 \pm 1.52$ & $55.15 \pm 13.88$ & $32.28 \pm 7.59$ \\
Naphthoquinone & $0.01 \pm 2.16$ & $0.015 \pm 1.67$ & $0.03 \pm 2.52$ \\
\hline
\end{tabular}

Values are means of three independent experiments

In-vitro antioxidant activities: The antioxidant activity of the samples was evaluated using DPPH and FRAP assays. Trolox was used as a reference (Table 3). The highest DPPH radical scavenging potential was observed for the $n$ - $\mathrm{BuOH}$ fraction demonstrating an activity corresponding to $121.1 \pm 4.9$ $\mu \mathrm{mol}$ Trolox equivalent/g of the extract. While the results of the FRAP assay showed that 9methoxyellipticine exhibited a remarkable 7.1-fold increase in ferric reducing power, followed by the $n$-BuOH and DCM fractions showing 2- and 1.7-fold increases in reduction efficiency compared to 
Trolox, respectively. Antioxidant agents usually function as inhibitors at both initiation and promotion/propagation/transformation stages of carcinogenesis, consequently protecting cells against oxidative damage [23]. The significant radical scavenging activity observed for the $n-\mathrm{BuOH}$ and DCM fractions can be attributed to their chemical constituents, where antioxidant activities have been previously reported for rutin [24], uvaol [17], lupeol and ursolic acid [16]. To the best of our knowledge, this is the first report of the antioxidant activity of O. elliptica leaves and 9methoxyellipticine.

Table 3. Anti-oxidant activity by DPPH and FRAP assays of the extracts and alkaloidal fractions of $O$. elliptica leaves

\begin{tabular}{lcc}
\hline Sample & \multicolumn{1}{c}{$\boldsymbol{\mu m o l ~ T r o l o x ~ e q . / g ~ e x t r a c t ~}$} & Anti-oxidant ratio* \\
& & \\
\hline Ethanol extract & $25.2 \pm 9.3$ & $1.8 \pm 0.00$ \\
DCM fraction & $47.5 \pm 9$ & $\mathbf{3 . 7} \pm \mathbf{0 . 2 8}$ \\
$n$-BuOH fraction & $\mathbf{1 2 1 . 1} \pm \mathbf{4 . 9}$ & $\mathbf{4 . 4} \pm \mathbf{0 . 2}$ \\
Alkaloidal fraction & $26.4 \pm 2.2$ & $0.4 \pm 0.05$ \\
9-methoxyellipticine $(\mathbf{8})$ & $0.42 \pm 0.12$ & $860 \pm 0 * *$ \\
Trolox & - & $2.1 \pm 0.01$ \\
\hline *Quantity of $\mathrm{Fe}^{2+}(\mathrm{nmol})$ reduced by $1 \mu \mathrm{g}$ extract & $* *$ Quantity of $\mathrm{Fe}^{2+}(\mathrm{nmol})$ reduced by 1 mg extract, Mean $\pm \mathrm{SD}$
\end{tabular}

In-vivo biological activities: The median lethal dose $\left(\mathrm{LD}_{50}\right)$ of the ethanolic extract of $O$. elliptica was determined and the results revealed that the extract is considered safe up to $5000 \mathrm{mg} / \mathrm{kg} \mathrm{b}$.wt.; indicated by no death occurring in both phases of the experiment.

Table 4. Effects of $O$. elliptica extracts and indomethacin on carrageenan-induced rat paw edema

\begin{tabular}{lccccl}
\hline \multirow{2}{*}{ Group } & $\begin{array}{c}\text { Dose } \\
\text { (mg/kg b.wt.) }\end{array}$ & $\mathbf{1 ~ h}$ & $\mathbf{2 ~ h}$ & $\mathbf{3 ~ h}$ & \multicolumn{1}{c}{$\mathbf{4}$ h } \\
\hline Indomethacin & 50 & 63.72276 & 61.67004 & 58.01383 & 59.32584 \\
& 250 & 71.10998 & 66.83547 & 60.06704 & 56.0206 \\
Ethanol extract & 500 & 72.1997 & 66.94801 & 63.70207 & 64.03558 \\
& 250 & 61.75874 & 54.70403 & 50.79614 & 49.1573 \\
DCM fraction & 500 & 61.50532 & 49.89872 & 44.2489 & 44.50375 \\
& 250 & 56.51292 & 52.27324 & 47.8106 & 45.67416 \\
$n$-BuOH fraction & 500 & 57.74202 & 52.74589 & 48.32391 & 40.6367 \\
\hline
\end{tabular}

Values are expressed as inhibition $\%(n=6)$

$* P<0.05$ statistically significant from the control normal inflamed group

In vivo anti-inflammatory activity: The anti-inflammatory activity of the ethanolic extract, DCM and $n$ - $\mathrm{BuOH}$ fractions of $O$. elliptica was evaluated by carrageenan-induced rat paw oedema method and the results are displayed in Table 4. The extracts were tested at two different dose levels and indomethacin was used as the standard drug. The experimental findings indicated that all extracts produced a reduction of oedema throughout the entire period of observation ( $1 \mathrm{~h}$ to $4 \mathrm{~h})$. The ethanolic extract displayed maximum effect at the first hour with the inhibition reaching $71 \%$ and $72 \%$ at 250 and $500 \mathrm{mg} / \mathrm{kg}$ b.wt, respectively, which was higher than indomethacin, exhibiting $63.7 \%$ inhibition at $50 \mathrm{mg} / \mathrm{kg}$ b.wt. The DCM fraction showed results comparable to indomethacin with \% inhibitions of $61.7 \%$ and $61.5 \%$ followed by the $n$-BuOH fraction showing $56.5 \%$ and $57 \%$, at doses of 250 and 500 $\mathrm{mg} / \mathrm{kg}$ b.wt, respectively. The percentage inhibition of all the tested extracts declined slightly by the third hour, while that of indomethacin persisted. Carrageenan induced rat paw oedema is a wellstudied model of acute inflammation widely used for evaluating anti-oedematous agents [25] and is typically associated with activation of the cyclo-oxygenase (COX) pathway. Indomethacin acts by blocking the two phases of oedema development i.e. blocking histamine and serotonin release within the first hour of oedema, and preventing release of some of the inflammatory mediators, via blocking the prostaglandin's action within the second phase [26]. The ethanolic extract, as well as, the DCM and $n$ - $\mathrm{BuOH}$ fractions of $O$. elliptica, appears to follow the same pattern as indomethacin with the 
inhibitory action being more pronounced at the first hour indicating a more pronounced effect on histamine and serotonin release. The significant anti-inflammatory activity observed for the ethanolic and the DCM fraction of $O$. elliptica could be attributed to a combination of the various phytochemicals detected viz; pentacyclic triterpenes, $\beta$-sitosterol glucoside and alkaloids. These results are in accordance with previous findings from the literature in which lupeol and lupeol acetate were reported to exhibit higher anti-inflammatory activity than indomethacin in rat and mouse models of inflammation $[27,28]$. Lupeol was reported to act as an anti-inflammatory agent with a mechanism similar to COX-selective inhibitor drugs [29], as well as, in-vitro inhibition of PGE2 and tumournecrosis factor- $\alpha$ [30]. Ursolic acid was as well reported to have anti-inflammatory, in addition to antioxidant and cytotoxic activities [31]. Ellipticine and 9-methoxyellipticine isolated from O. moorei were found to be active when tested in a pro-inflammatory gene down-regulation assay [32].

\section{Conclusion}

Cancer is considered a disease with numerous etiological factors and multiple culprits involved in its pathogenesis. It is clear that anti-inflammatory and antioxidant therapy is valuable towards early neoplastic progression and malignant transformation. Our study provides evidence for the efficacy of O. elliptica Labill. as a $\mathrm{Cdc} 25$ phosphatase inhibitor and a cytotoxic agent in treatment of breast cancer. Moreover, promising new anti-inflammatory and antioxidant activities were also established for the plant. Ochrosia elliptica leaves could also be considered a good source of 9-methoxyellipticine alkaloid which exhibited significant cytotoxic and antioxidant activities.

\section{Supporting Information}

Supporting information which accompanies this paper on http://www.acgpubs.org/RNP

\section{References}

[1] S. Goodwin, A. Smith and E. Horning (1959). Alkaloids of Ochrosia elliptica Labill, J. Am. Chem. Soc. 81, 1903-1908.

[2] M. Kuroda, Y. Mimaki, N. Kawase, A. Yokosuka, Y. Sashida, and A. Kagiya (1999). Cytotoxic alkaloids from the barks of Ochrosia elliptica, Nat. Med. 53, 272.

[3] Y. Liu, X. Wang, X. Li , K. Li, L. Huang and C. Wen, (2015). Studies on non-alkaloid constituents from Ochrosia elliptica, Zhongguo Zhong Yao Za Zhi 40, 1508-1513.

[4] N. C. Garbett and D. E. Graves (2004). Extending nature's leads: the anticancer agent ellipticine, Curr Med Chem Anticancer Agents 4, 149-172.

[5] R. Kizek, V. Adam, J. Hrabeta, T. Eckschlager, S. Smutny and J. V. Burda (2012). Anthracyclines and ellipticines as DNA-damaging anticancer drugs: recent advances, Pharmacol. Ther. 133, 26-39.

[6] M. Stiborová, J. Poljaková, E. Martínková E, J. Ulrichová J, V. Šimánek and Z. Dvořák (2012). Ellipticine oxidation and DNA adduct formation in human hepatocytes is catalyzed by human cytochromes P450 and enhanced by cytochrome b 5, Toxicology 302, 233-241 (2012).

[7] P. L. Kuo, Y. L. Hsu, Y. C. Kuo, C. H. Chang and C. C. Lin (2005). The anti-proliferative inhibition of ellipticine in human breast mda-mb-231 cancer cells is through cell cycle arrest and apoptosis induction, Anti-Cancer Drugs 16, 789-795.

[8] C. Savorani, V. Manfé, E. Biskup and R. Gniadecki (2015). Ellipticine induces apoptosis in T-cell lymphoma via oxidative DNA damage, Leuk. Lymphoma 56, 739-747.

[9] J. Poljaková, T. Eckschlager, J. Hraběta, J. Hřebačková , S. Smutný and E. Frei (2009).The mechanism of cytotoxicity and DNA adduct formation by the anticancer drug ellipticine in human neuroblastoma cells, Biochem. Pharmacol. 77, 1466-1479.

[10] J. N. Choi, Y.H. Choi, J.M. Lee, I.C. Noh, J.W. Park and W.S. Choi (2012). Anti-inflammatory effects of $\beta$-sitosterol- $\beta$-D-glucoside from Trachelospermum jasminoides (Apocynaceae) in lipopolysaccharidestimulated RAW 264.7 murine macrophages, Nat. Prod. Res. 26, 2340-2343.

[11] E. M. Hassan, A.A. Shahat, N.A. Ibrahim, A.J. Vlietinck, S. Apers and L. Pieters (2008). A new monoterpene alkaloid and other constituents of Plumeria acutifolia, Planta Med. 74, 1749-1750.

[12] C. S. Monnerat, J. J. d. Souza, L. Mathias, R. Braz-Filho and I. J. C. Vieira (2005). A new indole alkaloid isolated from Tabernaemontana hystrix Steud (Apocynaceae), J. Braz. Chem. Soc. 16, 1331-1335. 
[13] M. Chien and J. Rosazza (1980). Microbial transformations of natural antitumor agents: use of solubilizing agents to improve yields of hydroxylated ellipticines, Appl. Environ. Microbiol. 40, 741-745.

[14] D. Dolman, M. Sainsbury (1981). The synthesis of 8-hydroxy-and 8-methoxy-ellipticines, Tetrahedron Lett. 22, 2119-2120.

[15] W. Jordan, P. J. Scheuer (1965). Hawaiian plant studies-XIV alkaloids of Ochrosia sandwicensis A. Gray, Tetrahedron 21, 3731-3740.

[16] S. Javed, I.E. Oise, L. Nahar, F.M.D. I. Z. Mahmood and S.D. Sarker (2016). Isolation, identification and antiproliferative activity of triterpenes from the genus Monotheca A. DC, Rec. Nat. Prod. 10, 782-787.

[17] A. Mahapatra, P. Shah, M. Jivrajani and M. Nivsarkar (2015). Synthesis and blastocyst implantation inhibition potential of lupeol derivatives in female mice, Rec. Nat. Prod. 9, 561-566.

[18] V.R. Nagavelli, S. Narsimha, K.S. Battula, L. Sudhakar and R.K. Thatipamula (2016). Synthesis, cytotoxic and antibacterial activities of 6-bromobenzo[d]thiazol-2(3H)-one-[1,2,3] triazole hybrids, Org.Commun. 9, $32-41$.

[19] R. Boutros, C. Dozier and B. Ducommun (2006). The when and wheres of CDC25 phosphatases, Curr Opin Cell Biol 18, 185-191.

[20] S. Bonin, D. Brunetti, E. Benedetti, N. Gorji, G. Stanta (2006). Expression of cyclin-dependent kinases and CDC25a phosphatase is related with recurrences and survival in women with peri-and post-menopausal breast cancer, Virchows Arch. 448, 539-544.

[21] X. Xu, H. Yamamoto, M. Sakon , M. Yasui, C. Y. Ngan and H. Fukunaga (2003). Overexpression of CDC25A phosphatase is associated with hypergrowth activity and poor prognosis of human hepatocellular carcinomas. Clin Cancer Res 9, 1764-1772.

[22] S. Prasad, N. Nigam, N. Kalra and Y. Shukla (2008). Regulation of signaling pathways involved in lupeol induced inhibition of proliferation and induction of apoptosis in human prostate cancer cells, $\mathrm{Mol}$ Carcinog. 47, 916-924.

[23] D. Bagci, C. Sen, M. Bagci and M. Atalay (2004). Anti-angiogenic, antioxidant, and anti-carcinogenic properties of a novel anthocyanin-rich berry extract formula, Biochem (Mosc) 69, 75-80.

[24] J. Yang, J. Guo and J. Yuan (2008). In vitro antioxidant properties of rutin, Food Sci.Technol. 41, 10601066.

[25] A. Panthong, D. Kanjanapothi, T. Taesotikul, T. Wongcome and V. Reutrakul (2003). Anti-inflammatory and antipyretic properties of Clerodendrum petasites S. Moore, J. Ethnopharmacol. 85, 151-156.

[26] A. Gepdiremen, V. Mshvildadze, H. Süleyman and R. Elias (2005). Acute anti-inflammatory activity of four saponins isolated from ivy: alpha-hederin, hederasaponin-C, hederacolchiside-E and hederacolchisideF in carrageenan-induced rat paw edema, Phytomedicine 12, 440-444.

[27] E. Nguemfo, T. Dimo, A. Dongmo A, A. Azebaze A, K. Alaoui, and A. Asongalem (2009). Anti-oxidative and anti-inflammatory activities of some isolated constituents from the stem bark of Allanblackia monticola Staner LC (Guttiferae), Inflammopharmacology 17, 37-41.

[28] M. Saleem (2009). Lupeol, a novel anti-inflammatory and anti-cancer dietary triterpene, Cancer Lett. 285, 109-115.

[29] A. Fernández, A. Álvarez, M. D. García and M. T. Sáenz (2001). Anti-inflammatory effect of Pimenta racemosa var. ozua and isolation of the triterpene lupeol, Farmaco 56, 335-338.

[30] L. M. Lima, F. F. Perazzo, J. C. T. Carvalho and J. K. Bastos (2007). Anti-inflammatory and analgesic activities of the ethanolic extracts from Zanthoxylum riedelianum (Rutaceae) leaves and stem bark, $J$. Pharm. Pharmacol. 59, 1151-1158.

[31] Y. Ikeda, A. Murakami and H. Ohigashi (2008). Ursolic acid: An anti- and pro- inflammatory triterpenoid, Mol. Nutr. Food Res. 52, 26-42.

[32] A. R. Carroll et al. (2008). Alkaloids from the Australian rainforest tree Ochrosia moorei, J. Nat. Prod. 71, 1063-1065.

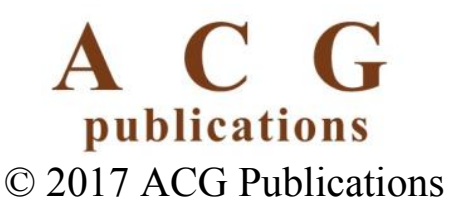

